Journal of Biotechnology and Strategic Health Research

\author{
Derleme / Review
}

http://dergipark.org.tr/tr/pub/bshr

\title{
COVID 19 Karaciğer Tutulumu ve Altta Yatan Karaciğer Hastalığı Olanlarda Hastalık Seyrinin İrdelenmesi
}

\section{COVID 19 Liver Involvement and Examination of Disease Prognosis in Patients with Underlying Liver Disease: A Review}

(D) \Ișıl Deniz Alıravc1 ${ }^{1}$, (DSevil Alkan Çeviker ${ }^{2}$

\author{
${ }^{1}$ Manavgat Devlet Hastanesi, Enfeksiyon Hastalıkları ve Klinik Mikrobiyoloji \\ ${ }^{2}$ Çanakkale Onsekiz Mart Üniversitesi, Tıp Fakültesi, Enfeksiyon Hastalıkları ve Klinik Mikrobiyoloji Anabilim Dalı, Çanakkale \\ ORCID ID: Işı1 Deniz Alıravcı https://orcid.org/0000-0002-4740-1579, Sevil Alkan Çeviker https://orcid.org/0000-0003-1944-2477 \\ ^Sorumlu Yazar / Corresponding Author: Uzm. Dr. Işıl Deniz Alıravcı, e-posta / e-mail: dr_isildeniz@hotmail.com \\ Geliş Tarihi / Received : 06-10-2020 Kabul Tarihi / Accepted: 09-12-2020 Yayın Tarihi / Online Published: 31-12-2020 \\ Alıravcı I.D., Alkan Çeviker S. COVID 19 Karaciğer Tutulumu ve Altta Yatan Karaciğer Hastalı̆̆ı Olanlarda Hastalık Seyrinin İrdelenmesi, \\ J Biotechnol and Strategic Health Res. 2020;4(3):206-211
}

Öz

COVID 19 pandemisi tüm dünyada olduğu gibi ülkemiz için de giderek artan öneme sahip olmaktadır. Bu virüsün yol açtığı klinik tabloların aydınlatılması, tedavi ve önleme çalışmaları global olarak devam etmektedir. Karaciğer tutulumunun da, SARSCoV-2 virüsünün karaciğer, safra ve karaciğer epitel hücrelerindeki ACE2 reseptörleri nedeniyle olabileceği bildirilmektedir. SARS-CoV infeksiyonu seyri sırasında sıklıkla ekstrapulmoner tutulum olabileceği ve hastaların neredeyse yarısının farklı derecelerde karaciğer fonksiyon hasarı yaşadığı bildirilmiștir. Bu infeksiyonun karaciğeri nasıl etkilediğine ve önceden var olan karaciğer hastalığının infeksiyona yakalanma veya ciddi bir hastalığa sahip olma risk faktörü olarak ilgisine ilişkin bilgiler hala yetersizdir. Önceki raporlar, COVID-19 hastalarının bir kısmının farklı derecelerde karaciğer fonksiyon anormalliği olduğunu göstermiştir. Bu derlemede SARS- CoV-2 infeksiyonunun karaciğer tutulumu ve öncesinde karaciğer hastalığı olan hastaların bu hastalık seyri açısından risk durumları hakkında güncel literatür eşliğinde gözden geçirme yapılması amaçlandı. COVID-19'lu bazı hastalarda yüksek karaciğer testleri ve / veya akut hepatit tablosu ile gelebileceğini akılda tutmalıyız. COVID-19 tanısı ile hastanede yatan hastalarda karaciğer fonksiyon testlerinde yaygın olarak yükselme görülse de, bu bulguların COVID-19'un bir belirtisi olduğu varsayılmamalıdır.Sonuç olarak; COVID-19 karaciğer tutulumu açısından henüz fikir biriliği gelişmediğinden ileriye yönelik çalışmalara ihtiyaç duyulmaktadır.

Anahtar COVID 19, karaciğer, ALT, AST.

Kelimeler

Abstract

The COVID 19 pandemic is of increasing importance for our country as well as all over the world. Studies of elucidation, treatment and prevention of the clinical pictures caused by this virus continue globally. It has been reported that liver involvement may be due to the ACE2 receptors in the liver, bile and liver epithelial cells of the SARS-CoV-2 virus. It has been reported that extrapulmonary involvement may occur frequently during the course of SARS-CoV infection and nearly half of the patients experience varying degrees of liver function damage. There is still insufficient information on how this infection affects the liver and the relevance of pre-existing liver disease as a risk factor for contracting or having a serious disease. Previous reports have shown that some of the COVID-19 patients have varying degrees of liver function abnormalities. In this review, it is aimed to review the risk of SARS-CoV-2 infection in terms of liver involvement and the course of this disease in patients with liver disease in the light of the current literature. We must keep in mind that some patients with COVID-19 may present with high liver tests and / or acute hepatitis. Although there is a widespread increase in liver function tests in hospitalized patients with a diagnosis of COVID-19, these findings should not be assumed to be a symptom of COVID-19. Since there is no consensus on COVID-19 liver involvement yet, further studies are needed.

Keywords COVID 19, liver, ALT, AST. 


\section{GíRiș}

2019'un sonunda, yeni bir koronavirüs olan severe acute respiratory syndrome coronavirus 2 (SARS-CoV-2), Çin'in Hubei Eyaletindeki bir şehir olan Wuhan'daki bir grup pnömoni vakasının nedeni olarak tanımlandı. Koronavirüs hastalığı 2019 (COVID-19), öncelikle hafif üst solunum yolu infeksiyonundan şiddetli pnömoniye, akut solunum sıkıntısı sendromuna (ARDS) ve ölüme kadar değişen semptomları olan bir akciğer infeksiyonu olarak kendini gösterdi ${ }^{1}$. Dünya Sağlık Örgütü (DSÖ) 30 Ocak 2020'de, SARS-CoV-2 salgınını pandemi olarak ilan etmiş olup; ilk vaka bildirilen tarihten itibaren ülkemiz verilerine göre; 302867 konfirme vaka, 7506 ölen; DSÖ verilerine göre ise 30.675.675 konfirme vaka, 954.417 ölen hasta sayısına ulaşan COVID 19 pandemisi tüm dünyada olduğu gibi ülkemiz için de giderek artan öneme sahip olmakta$d_{1}{ }^{2}$. Bu virüsün yol açtığı klinik tabloların aydınlatılması, tedavi ve önleme çalışmaları global olarak devam etmektedir. Bu infeksiyonun karaciğeri nasıl etkilediğine ve önceden var olan karaciğer hastalığının infeksiyona yakalanma veya ciddi bir hastalığa sahip olma risk faktörü olarak ilgisine ilişkin bilgiler hala yetersizdir. Önceki raporlar, COVID-19 hastalarının bir kısmının farklı derecelerde karaciğer fonksiyon anormalliği olduğunu göstermiştir ${ }^{3,4}$. $\mathrm{Bu}$ derlemede SARS- CoV-2 infeksiyonunun karaciğer tutulumu ve öncesinde karaciğer hastalığı olan hastaların bu hastalık seyri açısından risk durumları hakkında güncel literatür eşliğinde gözden geçirme yapılması amaçlandı.

\section{Mikrobiyoloji ve Patoloji}

Taksonomik açıdan incelendiğinde Beta-coronavirüs genusunun elemanı olan SARS-CoV-2, zarflı, pozitif yönelimli ve tek iplikçikli RNA virüsüdür. Hücrelere girişi anjiotensin converting enzim 2 (ACE 2) reseptör aracılığ ile olmaktadır ${ }^{5}$. SARS-CoV-2 virüsünün, SARS-CoV ile genom sekanslarına göre \%79.6 oranında benzerlik taşıdığı bildirilmektedir. Bu virüslerin ikisinin de konakçı hücresine girmesinin, konakçı hücre membranından salınan transmembrane serine proteaz (TMPRSS) ve ACE 2 reseptörlerine, spike (S) glikoproteinler aracılığıyla olduğu tahmin edilmektedir ${ }^{6-10}$. Özellikle SARS-CoV-2 virüsünün ACE 2 reseptörüne oldukça yüksek afinite gösterdiği saptanmıştır ${ }^{6-10}$. Karaciğer tutulumunun da, SARS-CoV-2 virüsünün karaciğer, safra ve karaciğer epitel hücrelerindeki ACE2 reseptörleri nedeniyle olabileceği bildirilmektedir ${ }^{11,12}$. SARS-CoV infeksiyonu seyri sirasinda sıklıkla ekstrapulmoner tutulum olabileceği ve hastaların neredeyse yarısının farklı derecelerde karaciğer fonksiyon hasarı yaşadığı bildirilmiştir ${ }^{13}$.

Xu ve ark. ${ }^{14}$ çalışmasında COVID 19 infeksiyonunda patolojik bulgu olarak karaciğer biyopsi örneklerinde orta derecede mikrovasküler steatoz ve hafif lobüler ve portal aktivitenin mevcut olduğunu bildirmiştir. Bu çalışmada karaciğer hasarının SARS-CoV-2 infeksiyonundan veya ilaca bağlı karaciğer hasarından kaynaklanabileceği saptanmıştır ${ }^{14}$. Farklı iki çalışmada ise; COVID-19 hastalarında karaciğer histolojisi spesifik olmadığı, hafif, karışık lobüler ve portal aktiviteye sahip orta derecede mikrovezikülersteatoz ve fokal nekroz dahil farklı patolojik bulgular olabileceği bildirilmiştir ${ }^{14,15}$. Sonzogni ve ark. ise ${ }^{16} 48$ olgudan oluşan otopsi serisinde, fokal portal-lobüler lenfositik infiltratları ve hepatik vasküler tutulumu düşündüren patolojik karaciğer bulgularının olduğunu bildirmiştir. Farcas ve ark. ${ }^{17}$ da karaciğer dokusunda yağlı dejenerasyon ve merkezi lobüler nekroz olduğunu göstermiştir. Farklı araştırmacılar tarafından bildirilen tüm bu bulguların tespit edilmesi nedeniyle, SARS-CoV-2'nin insan karaciğerine de saldırabileceğine inanmak için bilimsel kanıtlar bulunmaktadır ${ }^{13-17}$. Yapısal olarak SARS-CoV-2 virüsü SARS virüsüne benzese de, karaciğer dokusunda SARS virüsüne ait viral RNA tespit edilmiş olmasına rağmen, şu ana kadar yayınlanmış patoloji çalışmaları COVID 19 infeksiyonu seyri sırasında tutulum olabileceği yönünde olsa da, karaciğer dokusunda SARS-CoV-2 virüsüne ait olabilecek viral inklüzyonlar tespit edilememiştir ${ }^{14}$.

\section{Semptomlar, patofizyoloji ve anormal laboratuvar bulguları}

COVID 19 genellikle pulmoner semptomlara neden olur- 
ken, bazen yalnızca gastrointestinal semptomlarla da karşımıza çıkabilir. Ciddi kliniği olan olgularda gastrointestinal semptom görül-me olasılığının arttığı bildirilmektedir 10. Karaciğer tutulumu açısından değerlendirildiğinde ise; COVID-19'un klinik görünümü, akut hepatit benzeri belirtileri ve anormal karaciğer biyokimyasal testlerini içerebilirr ${ }^{18}$. SARS- CoV-2 infeksiyonu sırasında karaciğer enzimlerinde bozulma ilaca bağlı hepatotoksisite, kritik hastalarda sitokin fırtınası sırasında ya da pnömoni ile ilişkili hipoksi gibi nedenlere bağlı gelişebilir ${ }^{18,19}$.

3600 COVID-19 hastasını içeren 43 çalışmanın meta-analizinde, ateş [\% 83.3 (\% 95 CI 78.4-87.7)], öksürük [\% 60.3 (54.2-66.3)] ve yorgunluk [\% 38.0 (29.8-46.5) ] en yaygın klinik semptomlardı, ayrıca balgam, nefes darlığı ve miyaljinin ise \% 30'un biraz altında tahmini prevalansta görüldüğü bildirilmiştir ${ }^{20}$. Bulantı-kusma, anoreksi, karın ağrısı, ishal gibi gast-rointestinal semptomlar COVID 19 infeksiyonu seyri sırasında görülebilir ${ }^{21}$.

Genel olarak, COVID-19 infeksiyonu seyri sırasında, çeşitli çalışmalarda hastanede yatan hastalarda karaciğer biyokimyasal parametrelerine bakıldığında, hastaların \% 14 ile \% 53'inde Aspartat Aminotransferaz (AST), Alanin Aminotransferaz (ALT) ve hafif düzeyde bilirubin seviyelerinde yükselme olduğu bildirilmiştir. Ancak genel olarak bakıldığında COVID-19 hastalarında en sık görülen anormallik aminotransferaz (AST ve ALT) yüksekliğidir 3,13,18,21-23. Hem AST hem de ALT yükselmeleri çoğunlukla üst referans sınırının 5 katının altındadır ve şiddetli hastalık ve artmış iltihap belirteçleri ile ilişkilidir. AST ve ALT yükselmeleri ABD’li hastalarda (\% 39) Çin'li (\% 4-33) hastalara göre daha sık olarak bildirilmiştir ${ }^{24}$. Chen ve ark. 4 çalışmalarında 99 COVID-19 hastasını değerlendirmiş, 43 hastanın ALT-AST değerlerinin yüksek olduğu ve bir kritik COVID-19 hastasında ise ciddi hepatit tablosu görüldüğünü ve ALT değerinin $7590 \mathrm{U} / \mathrm{L}$, AST değerinin 1445 U/L’ye kadar yükseldiği bildirmiştir. Ancak bu hastanın demografik verisi, altta yatan hastalıkları ve mortalitesi hakkında veri paylaşılmamıştır.
Fan ve ark. ${ }^{13} 148$ COVID-19 hastasını inceledikleri çalışmalarında ayrıca, artmış Alkalen fosfataz (ALP) değeri varlığını araştırmışlar ve sonuç olarak ALP değerinin karaciğer fonksiyon hasarı olan hastalarda \%2-5 oranında olduğunu bildirmişlerdir. Bu çalışmada ayrıca, hastaların \%37.2 'inde aminotransferaz değerleri yüksek bulun $\neg$ muştur. Karaciğer enzim yüksekliği olan hastaların $\% 14,5$ inde ateş yüksekliği saptanırkan, karaciğer enzimlerinde yükselme olmayanlarda bu oran \%4.3 olarak saptanmıştır ( $\mathrm{p}=0.027)$. Karaciğer enzim yüksekliği olanlarda prokalsitonin ve C-reaktif protein (CRP) düzeyleri daha yüksek bulunmuş. Başvuru sırasında karaciğer enzimleri normal olan 93 hastanın 45'inde hastaneye yatış süresince enzim yüksekliği saptanmış. Karaciğer enzim yüksekliği olan hastalarda, lopinovir/ritonavir kullanımı daha fazla saptanmış aynı zamanda yatış süreleri daha uzun bulunmuştur ${ }^{10}$.

COVID-19 seyri sırasında karaciğer hasarının belirtileri genellikle hafiftir (orta derecede yükselmiş serum aspartat aminotransferaz aktiviteleri) ve genellikle asemptomatiktir. Karaciğer disfonksiyonu hastaların yaklaşık üçte birini etkileyebilir, prevalans erkeklerde ve yaşlılarda daha sık$\operatorname{tir}^{25}$.

Çin'den yapılan büyük bir çalışmada, şiddetli COVID-19 hastalarında daha yüksek karaciğer disfonksiyonu oranları olduğu saptanmıştır. AST / ALT hafif şiddetli COVID hastalarının sırasıyla \% 18,2 / 19,8'inde ve şiddetli COVID-19 hastalığı olanların\% 39,4 / 28,1'inde artmış olarak saptanmıştır ${ }^{26}$. Başka bir çalışmada subklinik hastalığı olan hastalarda AST ve ALT, sirasıyla hastaların\% 8.7 ve\% 8.9’unda yükselmiştir ${ }^{26}$. Yine Çin'de yapılan daha küçük bir başka çalışmada da benzer sonuçlar bulunmuştur. AST, yoğun bakım ünitesinde (YBÜ) hastaların \% 62'sinde yükselirken, YBÜ'de bakıma ihtiyaç duymayanların \% 25'inde yüksek olarak saptanmıştır³.

Richardson ve ark. ${ }^{27}$ Amerika'da 5700 hasta ile yaptıkları çalışmalarında vakaların \% 58,4'ünde AST ve \% 39'unda 
ALT değerlerinin yükseldiğini bildirmişlerdir. Aynı çalışmada en sık karaciğer fonksiyon bozukluğunun 18-65 (\%18.7\%) yaş arasında olduğu bildirilmiştir.

Ancak bazı çalışmalarda da, COVID-19 infeksiyonu seyri sırasında karaciğer disfonksiyonunun hafif, geçici olduğu, klinik olarak önemli olmadığı ve COVID-19 sonuçları üzerinde hiçbir etkisi olmadığı bildirilmiştir ${ }^{28,29}$.

Ancak, Xu ve ark. ${ }^{30}$ ise, hastaneye yatışta hepatoselüler tipte veya karışık tipte karaciğer testi anormal olan hastaların, hastanede kalış sırasında şiddetli hastalığa ilerleme riskinin daha yüksek olduğunu bildirmiştir.

Diğer iki çalışmada ise, COVID 19 infeksiyonu seyri sırasında, altta yatan karaciğer hastalığı olan hastalarda, öncesinde karaciğer hastalığı olmayanlara göre (\% 44-\%81) daha sık oranda karaciğer enzim yüksekliği tespit edildiği bildirilmiştir ${ }^{13,31}$.

Yayınlanan raporlar, AST' nin ALT'den daha sık yükseldiğini göstermektedir $21,23,28,31$. Bu durum, Gordon ve ark. 31 çalışmasında, SARS-CoV-2 virüsünün, mitokondriyal proteinlerin virüsle doğrudan etkileşime girerek, doğrudan karaciğer hasarına sebep olması sonucu AST yüksekliği geliştiği şeklinde açıklanmıştır.

Alkalin fosfataz yüksekliği nadirdir ve bilirübinde bir artış daha az yaygın olarak gözlemlenmiştir. Ancak ilginç bir şekilde, bir raporda vakaların yaklaşık olarak \% 50'sinde yüksek gama-glutamiltransferaz (GGT) seviyeleri olduğu bildirilmiştir $^{32}$. AST ön planda karaciğer enzim yüksekliği ve eşlik eden GGT yüksekliği, altta yatan alkolik, iskemik veya konjestif kalp yetmezliği olan hastalarda bildirilmektedir $^{33}$. Zhang ve ark. 1856 COVID-19 olgusunu kapsayan çalışmalarında, \%54 oranında GGT değe $\neg$ rinde artış saptamışlardır. Total bilirubin yüksekliği COVID-19 hastalarının \% 1-18'i arasında geliştiği bildirilmektedir ${ }^{24}$.

COVID 19 infeksiyonu seyrindeki karaciğer hasarının güçlü inflamatuar yanıta neden olan IL-6’ya bağlı olabileceği bildirilmiştir ${ }^{34}$. IL- 6 , aktive B hücrelerinden antikor salınımını uyararır, megakaryositler,sitotoksik T-hücreleri ve diğer hemopoetik hücreler üzerinde proliferasyon ve diferansiyasyon sağlayıcı etkileri vardır. Hepatik akut faz proteinlerinin salınımı, megakaryositleri etkileyerek trombosit oluşumu, mezenşial hücre proliferasyonu, plazma hücreleri tarafından immünoglobulinlerin yapımının uyarılması, vasküler endotelyal büyüme faktörü (VEGFR)'nü arttırarak anjiogenez oluşumuna ve kardiomiyopatiye neden olur. IL-6, dissemine intravascular koagulasyon (DIC) patofizyolojisinde, kompleman ve koagülasyon sistemini aktive edilmesinde rol alır. Tüm bu özellikleri nedeniyle IL-6, sitokin fırtınasında anahtar moleküldür ${ }^{35}$.

Amerika Birleşik Devletleri’nde yapılan bir çalışmada, COVID-19 infeksiyonu olan hastaların \% 33'ünde kardiyomiyopati saptanmıştır ${ }^{36}$. Bu nedenle, şiddetli hastalarda kardiyak disfonksiyon sonucu gelişen karaciğer konjesyonunun karaciğer hasarına katkıda bulunması mümkündür. COVID 19 infeksiyonu seyri sırasinda akut kardiyomiyopatinin bir sonucu olarak konjestif hepatopati meydana gelebilir ve bu durum genellikle aminotransferazlar (AST, ALT) ve GGT'deki yükselmelerle ilişkilidir ${ }^{37,38}$.

Çeşitli çalışmalarda, düşük albümin düzeyi, şiddetli COVID-19 infeksiyonu ile ilişkilendirilmiştir. Bununla birlikte, hipoalbümineminin şiddetli COVID-19 için bir risk faktörü olup olmadığı veya hipoalbümineminin şiddetli COVID-19’un bir sonucu olup olmadığ açık değildir ${ }^{14,34}$.

Fan ve ark. ${ }^{13} 148$ COVID-19 hastasında ilaç kullanımı ve aminotransferazlar arasındaki ilişkiyi geriye dönük olarak incelemiş ve başvuru sırasında aminotransferaz anormalliği olmayan hastaların \% 48'inde yaklaşık bir hafta sonra ALT/ AST yüksekliği geliştiğini bildirmişlerdir. Bu hastaların \% 58'inde lopinavir-ritonavir kullanımı olduğunu bildirmiştir ${ }^{13}$. Cai ve ark. ${ }^{31}$ lopinavir-ritonavir kullanımından sonra ALT/ AST yüksekliği için, 7 kat artmış risk olduğunu bildirmiştir.Tedavide kullanılan bir diğer antiviral 
olan remdesivir için, 5 veya 10 günlük tedaviyi karşılaştıran bir çalışmada, hastaların\% 4-6’sında şiddetli ve \% 2-3'ünde ise yaşamı tehdit eden ALT / AST yükselmeleri olduğunu bildirilmiştir ${ }^{39}$.

Anormal karaciğer enzim yüksekliği olan COVID-19 hastalarının komplikasyonları ve dolayısıyla mortalitelerinin azaltılması için; kalp fonksiyon bozukluğu, sitokin fırtınası, iskemi, sepsis ve ilaç etkisi açısından değerlendirilmesi gerekir ${ }^{40}$.

\section{Kronik karaciğer hastalığı olan COVID-19 hastalarına yaklaşım}

Kronik karaciğer hastalığı olan hastaların SARS-CoV-2 infeksiyonuna daha duyarlı olup olmadığı belirsizdir. İmmünsüpresif tedavi yokluğunda kronik karaciğer hastalığının SARS-CoV-2 infeksiyonu kapma riskinde artış ile ilişkili olduğu bilinmemektedir ${ }^{41}$. COVID-19 infeksiyonu sırasında karaciğer tutulumu ortaya çıkarsa, dikkatli olunması gerekir. Bu, özellikle hastalar yaşliysa veya önceden var olan bir karaciğer hastalığı geçmişine sahipse geçerlidir. COVID-19 infeksiyonu sırasında, karaciğer hasarının olması prognozu bozar ve hastanede kalış süresinin uzamasına sebep olur ${ }^{25}$. Karaciğer fonksiyon testleri, yükselmiş hastalarda önceden var olan karaciğer hastalığının varlığı çoğu çalışmada kapsamlı bir şekilde değerlendirilmemiştir, ancak hepsini hesaba katması olası değildir. Ayrıca; her ne kadar anormal karaciğer fonksiyon testleri zaten sıklıkla COVID 19 infeksiyonuna bağlı olabileceği gibi, potansiyel olarak tedavide kullanılan hepatotoksik olan asetaminofen, lopinavir / ritonavir ve remdesivir sonucu da gelişebilir ${ }^{24}$.

Singh ve ark. ${ }^{42}$ tarafından yapılan çalışmada, $2780 \mathrm{CO}$ VID-19 hastası (kronik karaciğer hastalığı olan 250 hasta dahil) değerlendirilmiş, kronik karaciğer hastalığı olan hastalarda, karaciğer hastalığı olmayanlara kıyasla daha yüksek mortalite geliştiği bildirilmiştir (yüzde 12'ye karşı 4; risk oranı [RR] 2.8, \% 95 CI 1.9-4.0)
Güncel literatürde; önceden var olan karaciğer hastalığının COVID-19 hastalarında daha kötü sonuçlarla ilişkili olduğunu ileri süren çeşitli çalışmalar mevcuttur ${ }^{42-5}$. Moon ve ark. ${ }^{43}$ kohort çalışmasında, COVID-19 ve kronik karaciğer hastalığı olan 152 hastayı (sirozlu 103 hasta dahil) içeren bir kohort çalışmasında, ölüm oranını \% 40 olarak bildirmiştir. Bu çalışmada hastalar; Child-Pugh (CP) sınıflamasına göre siroz hastaları A,B ve C ye ayrılmış olup, mortalite oranları gruplara göre sırayla; \%23,43 ve 63 olarak bildirilmiştir. Sirozlu hastalarda ölüm, çoğunlukla akciğer hastalığına (\% 79) atfedilirken, sadece karaciğer hastalığ-na bağlı nedenler hastaların \% 12'sinde saptanmıştır.

Buna karşın HBV veya hepatit C virüsü (HCV) infeksiyonu olan hastalar için antiviral tedavi, şiddetli COVID-19 için artmış risk ile ilişkilendirilmemiştir ${ }^{46}$.

Ayrıca; karaciğer nakli alıcıları ve COVID-19'u olan diğer bağışıklık sistemi baskılanmış hastalar, bağışıklık sistemi baskılanmamış hastalara göre daha uzun viral bulaşma süresine sahip olabilir. Bu nedenle, izolasyon ve klirens testi için stratejiler, infeksiyonun başkalarına yayılma riskini azaltmak için değişiklik gerektirebilir ${ }^{46}$.

COVID-19'lu bazı hastalarda yüksek karaciğer testleri ve / veya akut hepatit tablosu ile gelebileceğini akılda tutmalıyız. COVID-19 tanısı ile hastanede yatan hastalarda karaciğer fonksiyon testlerinde yaygın olarak yükselme görülse de, bu bulguların COVID-19'un bir belirtisi olduğu varsayılmamalıdır. Bu hastalar için, öncelikle karaciğer enzim yüksekliğinin etiyolojisini belirlemeye yönelik iyi bir anamnez alınmalı ( ilaç, toksin, kronik karaciğer hasarı) ve tanısal değerlendirme yapılmalıdır (hepatit markerları, batın ultrasonografi, vs. $)^{40,46}$.

Sonuç olarak; COVID-19 karaciğer tutulumu açısından henüz fikir birliği gelişmediğinden ileriye yönelik çalışmalara ihtiyaç duyulmaktadır. Yazarlar arasında çıkar çatışması veya finansal destek yoktur. 


\section{Kaynaklar}

1. Centers for Disease Control and Prevention. 2019 Novel coronavirus, Wuhan, China. Information for Healthcare Professionals. https://www.cdc.gov/coronavirus/2019-nCoV/hcp/index. html (Accessed on February 14, 2020).

2. https://covid19.tubitak.gov.tr/ (erișim tarihi 21.09.2020)

3. Huang C, Wang Y, Li X, Ren L, Zhao J, Hu Y, et al. Clinical features of patients infected with 2019 novel coronavirus in Wuhan, China. Lancet 2020:395;497-506. doi:10.1016/S01406736(20)30183-5

4. Chen N, Zhou M, Dong X, Jieming Q, Gong F, Han Y,et al. Epidemiological and clinical characteristics of 99 cases of 2019 novel coronavirus pneumonia in Wuhan, China: a descriptive study. Lancet 2020:395;507-513. doi:10.1016/S0140-6736(20)30211-7.

5. Wu $F$, Zhao $S, Y u$ B, Chen $Y M$, Wang $W$, Song $Z G$, et al. A new corona virus associated with human respiratory disease in China. Nature. 2020; 579:265-269. https://doi.org/10.1038/ s41586-020-2008-3

6. Zhou P, Yang XL, Wang XG, Hu B, Zhang L, Zhang W, et al. A pneumonia outbreak asso $\neg$ ciated with a new coronavirus of probable bat origin. Nature 2020; 579: 270- 273

7. Lu R, Zhao X, Li J, Niu P, Yang B, Wu H, et al. Genomic characterisation and epide-miology of 2019 novel coronavirus: implications for virus origins and recept or binding. Lancet 2020; 395: 565- 574.

8. Hoffmann M, Kleine Weber H, Schroeder S, Krüger N,Herrler T, Erichsen S, et al. SARS-CoV-2 Cell Entry Depends on ACE2 and TMPRSS2 and Is Blocked by a Clinically Proven Protease Inhibitor. Cell 2020:181; 271-280.

9. Tortorici MA, VeeslerD. Structural insights into coronavirus entry. Adv Virus Res. 2019:105; 93-116. doi: 10.1016/bs.aivir.2019.08.002

10. Derviș Hakim G, Özer Sarı S. Covid-19 ve Sindirim Sistemi. Tepecik Eğit. ve Arașt. Hast. Dergisi 2020;30(Ek sayl):112-117. doi:10.5222/terh.2020.96630

11. Chai X, Hu L, Zhang Y, Han W. ACE2 expression in cholangiocytes may cause liver damage after 2019-nCoV infection. bioRxiv 2020. doi: https://doi.org/10.1101/2020.02.03.931766

12. XiaoqiangChai LH, Yan Zhang. Specific ACE2 expression in cholangiocytes may cause liver damage after 2019-nCoV infection. bioRxiv 2020. (Preprint) Available at: 10.1101/2020.02.03.931766. Accessed February 20, 2020

13. Fan Z, Chen L, Li J, Cheng X, Yang J, Tian C, Zhang Y, Huang S, Liu Z, Cheng J. Clinical Features of COVID-19-Related Liver Functional Abnormality. Clin Gastroenterol Hepatol. 2020;18(7):1561-1566. doi: 10.1016/j.cgh.2020.04.002. Epub 2020 Apr 10. PMID: 32283325; PMCID: PMC7194865

14. Xu Z, Shi L, Wang Y. Pathological findings of COVID-19 associated with acute respiratory distress syndrome. Lancet Respir Med. 2020;8:420-422.

15. Yao XH, Li TY, He ZC, Ping YF, Liu HW, Yu SC, et al. A pathological report of three COVID-19 cases by minimal invasive autopsies. 2020;49(5):411-417.

16. Sonzogni A, Previtali G, Seghezzi M, Alessio MG, Gianatti A, Licini L, et al. Liver and COVID 19 infection: A very preliminary lesson learnt from histological post-mortem findings in 48 patients. Preprints 2020. doi: 10.20944/preprints202004.0438.v1

17. Farcas GA, Poutanen SM, Mazzulli T. Fatal severe acute respiratory syndrome is associated with multiorgan involvement by coronavirus. J InfectDis. 2005;191:193-197.

18. Zhang C, Shi L, Wang FS. Liver injury in COVID-19: management and challenges. Lancet Gastroenterol Hepatol 2020; 5:428

19. Redd WD, Zhou JC, Hathorn KE, McCarty TR, Bazarbashi AN, Thompson CC, et al. Prevalence and Characteristics of Gastrointestinal Symptoms in Patients With Severe Acute Respiratory Syndrome Coronavirus 2 Infection in the United States: A Multicenter Cohort Study. Gastroenterology 2020; 159:765-767.doi: 10.1053/j.gastro.2020.04.045

20. APASL Covid-19 Task Force, Lau G, Sharma M. Clinical practice guidance for hepatology and liver transplant providers during the COVID-19 pandemic: APASL expert panel consensus recommendations. Hepatol Int. 2020 Jul;14(4):415-428. doi: 10.1007/s12072-020-10054-w. Epub 2020 May 23. PMID: 32447721; PMCID: PMC7245190.

21. Xu L, Liu J, Lu M, Yang D, Zheng X. Liver injury during highly pathogenic human coronavirus infections. Liver Int. 2020 40(5):998-1004. doi: 10.1111/liv.14435.

22. Xie H, Zhao J, Lian N, Lin S, Xie Q, Zhuo H. Clinical characteristics of Non-ICU hospitalized patients with coronavirus disease 2019 and liver injury. A Retrospective study. Liver Int. 2020. 10.1111/liv.14449.doi: 10.1111/liv.14449

23. Guan WJ, Ni ZY, Hu Y, Liang WH, Ou CQ, He JX, et al. Clinical characteristics of coronavirus disease 2019 in China. N Engl J Med 2020; 382:1708-1720 doi: 10.1056/NEJMoa2002032 2020.

24. Bertolini A, van de Peppel IP, Bodewes FAJA, et al. Abnormal liver function tests in COVID-19 patients: relevance and potential pathogenesis. Hepatology 2020. Version of Record. doi: 10.1002/hep. 31480

25. Portincasa P, Krawczyk M, Machill A, Lammert F, Di Ciaula A. Hepatic consequences of COVID-19 infection. Lapping or biting? Eur J Intern Med. 2020 Jul;77:18-24. doi: 10.1016/j. ejim.2020.05.035. Epub 2020 Jun 1. PMID: 32507608; PMCID: PMC7262543.

26. Shi H, Han X, Jiang N, Cao Y, Alwalid O, Gu J, Fan Y, Zheng C. Radiological findings from 81 patients with COVID-19 pneumonia in Wuhan, China: a descriptive study. Lancet Infect Dis. 2020;20(4):425-434. doi: 10.1016/S1473-3099(20)30086-4.

27. Richardson S, Hirsch JS, Narasimhan M, Crawford JM, McGinn T, Davidson KW; the Northwell COVID-19 Research Consortium, et al. Presenting Characteristics, Comorbidities, and Outcomes Among 5700 Patients Hospitalized With COVID-19 in the New York City Area [published correction appears in JAMA. 2020 May 26;323(20):2098]. JAMA. 2020;323(20):20522059. doi:10.1001/jama.2020.6775

28. Girardi E, Petrosillo N, Aloisi MS, Ravà L, Ippolito G. Peer-reviewed articles and public health: the mad cow affair in Italian news papers. JAMA. 1998: 15;280(3):292-4. doi: 10.1001/ jama.280.3.292. PMID: 9676687.

29. Ridruejo E, Soza A.Theliver in times of COVID-19: What hepatologists should know. Annals of Hepatology. 2020:19; 353-358.

30. Xu L, Beckebaum S, Iacob S, Wu G, Kaiser GM, et al. MicroRNA-101 inhibits human he patocellular carcinoma progression through EZH2 down regulation and increased cytostati drug sensitivity. J Hepatol. 2014;60(3):590-8. doi: 10.1016/j.jhep.2013.10.028. Epub 2013 Nov 6. PMID: 24211739.

31. Cai Q, Huang D, Yu H, Zhu Z, Xia Z, Su Y,et al. Characteristics of liver tests in COVID-19 patients. J Hepatol 2020. https://doi.org/10.1016/j. jhep.2020.04.006

32. Gordon DE, Jang GM, Bouhaddou M, Xu J, Obernier K, White KM, et al. A SARS-CoV-2 protein interaction map reveals targets for drug repurposing. Nature. 2020: 583;459-468. doi. org/10.1038/s41586-020-2286-9

33. Pratt DS, Kaplan MM. Evaluation of abnormal liver-enzyme results in asymptomatic patients. N Engl J Med 2000;342:1266-1271.

34. Arentz M, Yim E, Klaff L, Lokhandwala S, Riedo FX, Chong M, et al. Characteristics and outcomes of 21 critically ill patients with COVID-19 in Washington State. JAMA 2020;323:16121614. doi: 10.1001/jama.2020.4326

35. Doğan Ö, Devrim E. Tanı ve İzlemde Laboratuvar Testleri. COVID-19-Kitap. Bölüm 4. S 30-34. http://www.medicine.ankara.edu.tr/wp-content/uploads/sites/121/2020/05/COVID-19-Kitap.pdf

36. Blanco-Melo D, Nilsson-Payant BE, Liu WC, Uhl S, Hoagland N, Møller R, et al. Imbalanced host response to SARS-CoV-2 drives development of COVID-19. Cell. 2020:5; 1036-1045.e9. doi:10.1016/j.cell.2020.04.026

7. Weisberg IS, Jacobson IM. Cardiovascular diseases and the liver. Clin Liver Dis 2011:15:1-20.

38. vanDeursen VM, Damman K, Hillege HL,Beek V, Van Veldhuisen DJ, Voors AA, et al. Abnormal liver function in relation to hemodynamic profile in heart failure patients. J Card Fail 2010;16:84-90.

39. Goldman ID, Lye DCB, Hui DS, Marks KM, Bruno R, Montejano R, et al. Remdesivir for 5 or 10 Days in Patients with Severe Covid-19. N. Engl. J. Med. [Internet]. 2020;Available from: https://doi.org/10.1056/nejmoa2015301

40. American Association for the Study of Liver Diseases. Clinical Insights for Hepatology and Liver Transplant Providers During the COVID-19 Pandemic. https://www.aasld.org/sites/ defau lt files/2020-04/AASLD-COVID 19-Clini calIn sights-April 162020-FINAL.pdf. Published April 7,2020

41. Zhang C, Shi L, Wang FS. Liver injury in COVID-19: management and challenges. Lancet Gastroenterol Hepatol 2020; 5:428.

42. Singh S, Khan A. Clinical Characteristics and Outcomes of Coronavirus Disease 2019 Amon Patients With Preexisting Liver Disease in the United States: A Multicenter Research Network Study. Gastroenterology 2020; 159:768.

43. Moon AM, Webb GJ, Aloman C, Armstrong MJ, Cargill T, Dhanasekaran R, et al. High mor tality rates for SARS-CoV-2 infection in patients with pre-existing chronic liver disease and cirrhosis: Preliminary results from an international registry. J Hepatol. 2020;73(3):705-708. doi: 10.1016/j.jhep.2020.05.013. Epub 2020 May 21. PMID: 32446714; PMCID: PMC7241346. CDC COVID-19 Response Team. Preliminary Estimates of the Prevalence of Selected Underying Health Conditions Among Patients with Coronavirus Disease 2019 - United States, February 12-March 28, 2020. MMWR Morb Mortal Wkly Rep 2020; 69:382.

44. Ji D, Qin E, Xu J, Zhang D, Cheng G, Wang Y, et al. Non-alcoholic fatty liver diseases in patients with COVID-19: A retrospective study. J Hepatol. 2020 Aug;73(2):451-453. doi: 10.1016/j. jhep.2020.03.044. Epub 2020 Apr 8. PMID: 32278005; PMCID: PMC7141624.

45. Williamson E, Walker AJ, Bhaskaran KJ, Bacon S, Bates C,Morton CE, et al. Open SAFELY: Factors associated with COVID-19-related hospital death in the linkedel ectronic health records of 17 million adult NHS patients. MedRxiv 2020. medRxiv 2020.05.06.20092999; doi: https:// doi.org/10.1101/2020.05.06.20092999

46. https://www.uptodate.com/contents/coronavirus-disease-2019-covid-19-issues-related-to-liver-disease-in-adults\#references 